\title{
Correction to: Analysis of Population-Genetic Properties of Copy Number Variations
}

\author{
Lingyang Xu, Liu Yang, Derek M. Bickhart, JunYa Li, \\ and George E. Liu
}

\section{Correction to}

Chapter 14 in: Derek M. Bickhart (ed.), Copy Number Variants:

Methods and Protocols, Methods in Molecular Biology, vol. 1833, https://doi.org/10.1007/978-1-4939-8666-8_14

The original version of the book was inadvertently published with incorrect spelling of the author name "Liu Yang". The author name has now been corrected.

\footnotetext{
The updated online version of this chapter can be found at https://doi.org/10.1007/978-1-4939-8666-8_14 https://doi.org/10.1007/978-1-4939-8666-8
} 